\title{
An Evaluation of the Impact of Climate Change on Runoff in the Upper Reaches of Yangtze River, China
}

\author{
Changqing Meng, Jianzhong Zhou, Minglong Dai, and Wei Li
}

\begin{abstract}
The impact of future climate change on the streamflows for the upper reaches of Yangtze River, China, has been investigated with the Variable Infiltration Capacity (VIC) model. VIC model was applied to the upper reaches of Yangtze River with the calibration period of 1962-1990, and validation period of 1991-2010. Then the future climate change scenarios derived from five general circulation models (GCMs) under scenario Representative Concentration Pathway 4.5 (RCP4.5) were projected to the calibrated VIC model to study the hydrological processes. Results demonstrated that the VIC model can satisfactorily simulate the rainfall-runoff processes. The results showed that the projected streamflow decreased slightly in January to June but increased significantly from August to October. The coefficient of variation (CV) under projected climate increased in summer and annual, decreased in winter.
\end{abstract}

Index Terms-VIC model, GCMs, climate change on runoff.

\section{INTRODUCTION}

The climate warming has increased the evaporation and changed the runoff which has altered the hydrological cycle and affected human activities. Researching the variation of streamflows caused by the complex meteorological conditions has drawn more and more attention.

The GCMs is a type of climate model which numerically simulate the 'state' of the atmosphere and has been the effective tools to explore the impacts of climate change on streamflows. Zhang et al. (2016) [1] examined the streamflow change based on different GCMs and demonstrated the increasing tendency for drought and flood events in October in the future. Shrestha et al. (2015) [2] evaluated the ability of VIC model to replicate different water indicators by inputting observed data and GCMs. Bae et al. (2014) [3] inputted three GCMs to VIC model to investigate the future climate change impacts on water resources. The above applications demonstrate that the VIC model coupled GCMs is a good solution for assessing variations in water resources under future climate change.

In this paper, the VIC model is used to build the rainfall-runoff model. The historical data is used to calibrate

Manuscript received September 6, 2016; revised February 3, 2017.

Changqing Meng, Minglong Dai, and Minglong Dai are with the School of Hydropower and Information Engineering, Huazhong University of Science and Technology, Wuhan 430074, China (e-mail: D201377808@hust.edu.cn,_ D201377811@hust.edu.cn, 2736325098@qq.com).

Jianzhong Zhou is with the School of Hydropower and Information Engineering, Huazhong University of Science and Technology, Wuhan 430074, China. He is also with HuBei Key Laboratory of Digital Valley Science and Technology, Wuhan, 430074, China (e-mail: jz.zhou@hust.edu.cn) and validate the VIC model. Then five GCMs of RCP4.5 are projected to study hydrological processes in future periods (2020-2049, 2050-2079, 2080-2099).

\section{StUdy AREA}

The upper reaches of Yangtze River is located in the northwest of China, which flows through Tibet, Qinghai, Sichuan, Yunan and Chongqing provinces. The region is characterized by wide climate zones varying from humid to arid environments with an area of $866.8 \times 103 \mathrm{~km} 2$. With the characteristics of uneven spatial distribution, mean annual temperature and precipitation ranges from $-4.5^{\circ} \mathrm{C}$ and $312 \mathrm{~mm}$ to $16.6^{\circ} \mathrm{C}$ and $1652 \mathrm{~mm}$. The mean annual temperature and precipitation are increasing gradually from northwest to southeast and on the contrary, the elevation is reducing. Due to the effects of monsoon climate, floods occurs frequently during the rainy season from May-October over the basin and for dry season, the occurrence frequency of droughts is also high. Fig. 1 shows the location of the upper reaches of Yangtze River.

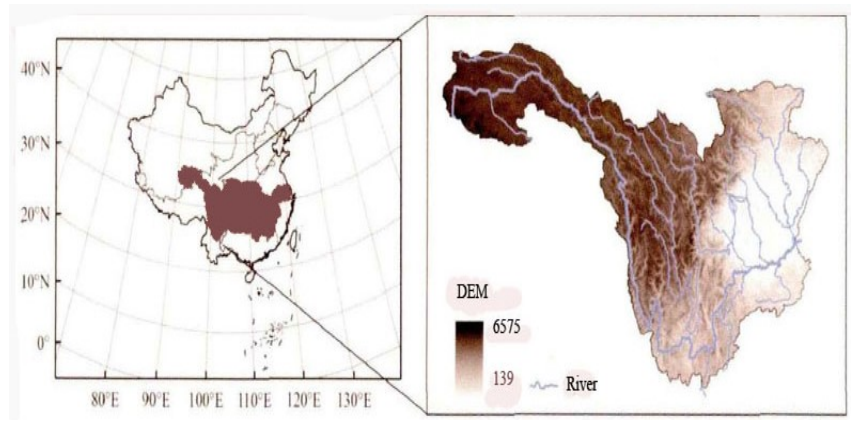

Fig. 1. Location of the upper reaches of Yangtze River.

\section{DATA AND METHODOlOGY}

\section{A. VIC Model Description}

The variable infiltration capacity (VIC) land surface model (Liang 1994 [4], 1996 [5]) is a hydrological based land surface scheme that explicitly represents the effects of the spatial variability of infiltration, precipitation, and vegetation on water fluxes through the landscape. In recent years, the VIC model have been applied to various basins of different scales with good performance (Park and Markus 2014 [6]; Yan et al. 2015 [7]; Shrestha et al. 2015 [2]). The applications also have covered many research areas, from studies of simulating ensembles of streamflow, global flood estimation, uncertainty analysis of climate data and model parameter sets, and the influence of land-use and climate change on 
streamflow processes.

\section{B. Datasets}

50 meteorological (1960-2010) stations provided daily precipitation data, maximum temperature, minimum temperature. The daily observed streamflow time series at Cuntan guage station from1962-1990 were used to calibrate the model, data from 1991-2010 were used to validate its performance, and warm-up data from 1960-1961 was used to reduce sensitivity to state-value initialization errors. Daily climate variables required by the VIC model are interpolated to $0.5 \times 0.5$ degree resolution by the Theisen Polygon method between the rain gauges and the grid cells [8]. Future daily precipitation, maximum temperature, minimum temperature of this research include five global climate models (GFDL-ESM2M, HadGEM2-ES, IPSL-CM5A-LR, MIROC-ESM-CHEM, and NorESM1-M) were derived from ESGF (Earth System Grid Federation) (http://esgf.llnl.gov/). This set of data was linearly interpolated to the grid of $0.5 \times 0.5$ resolution and RCP4.5 was applied to research.

\section{Assessment Criteria}

Two objective functions are selected to evaluate the model performance, including the relative error (RE), Nash and Sutcliffe (1970) efficiency coefficient (NSE).

$$
\begin{aligned}
\mathrm{NSE}= & \left(1-\frac{\sum_{i=1}^{n}\left(Q_{\mathrm{i}}-\widehat{Q}_{\mathrm{i}}\right)^{2}}{\sum_{\mathrm{i}=1}^{n}\left(Q_{\mathrm{i}}-\bar{Q}_{\mathrm{i}}\right)^{2}}\right) \times 100 \\
\mathrm{RE}= & \left(\frac{\sum_{i=1}^{n} \widehat{Q}_{i}}{\sum_{i=1}^{n} Q_{i}}-1\right) \times 100
\end{aligned}
$$

where $Q_{i}$ is the observed streamflow $\left(\mathrm{m}^{3} / \mathrm{s}\right), \hat{Q}_{i}$ is the simulated streamflow $\left(\mathrm{m}^{3} / \mathrm{s}\right)$ and $\bar{Q}_{\mathrm{i}}$ is mean observed streamflow $\left(\mathrm{m}^{3} / \mathrm{s}\right)$.

\section{RESUlTS AND DISCUSSION}

\section{A. VIC Model Calibration and Validation}

The VIC model was established and forced by meteorological data, DEM, land use, soil data. The shuffled complexes evolution global optimization algorithm (SCE-UA) was applied to calibrate the VIC model parameters [9]. Fig. 2 shows the time series of the observed and simulated discharges of Cuntan station. It can be seen from the Fig. 1 that the simulated discharges are consistent with the observed discharges. Table I shows the VIC model performance for calibration and validation period at daily, monthly and yearly scales. Table II reveals that the VIC model performance is acceptable with the NSE values of $82.87 \%$ and $80.08 \%$, and the RE values of $2.24 \%$ and $-2.16 \%$. It is also can be found that with longer timescales better results will be achieved.
TABLE I: Vic MODEL PERFORMANCE FOR CALIBRATION AND VALIDATION PERIODS OF HISTORY PERIOD

\begin{tabular}{lcc} 
Period & NSE(\%) & RE(\%) \\
\hline Daily & & \\
Calibration & 82.87 & 2.24 \\
Validation & 80.08 & -2.16 \\
Monthly & & \\
Calibration & 92.86 & 2.20 \\
Validation & 91.63 & -2.21 \\
Yearly & & \\
Calibration & 94.28 & 2.24 \\
Validation & 94.73 & -2.16 \\
\hline \hline
\end{tabular}

\section{B. Hydrological Response of Runoff to Future Climate}

\section{1) Change of meteorological elements}

In order to reduce uncertainties of single GCMs, we use the GCMs' ensemble to assess the change of meteorological elements [10]. Fig. 3 presents the monthly mean precipitation, Tmax, Tmin and streamflows of three future periods comparing the historical data. Fig. 3(a) shows that the future precipitation increased from July to September and precipitation of other months was close to the historical scenarios. The annual precipitation of GCMs in three future periods increased $3.17 \%, 8.04 \%$ and $11.94 \%$, respectively. Fig. 3(b)-(c) show that the future Tmax and Tmin increased significantly from January to June. The annual Tmax of GCMs in three future periods increased $0.39^{\circ} \mathrm{C}, 1.05^{\circ} \mathrm{Cand}$ $1.48^{\circ} \mathrm{C}$, respectively. Compared to Tmax, the magnitude of annual variations in Tmin was weaker with the value of $0.07^{\circ} \mathrm{C}, 0.61^{\circ} \mathrm{C}, 1.04^{\circ} \mathrm{C}$ for each future period. Fig. $3(\mathrm{~d})$ shows that the future streamflow decreases slightly in January to June but increased from August to October. The results suggest that streamflows will more intensify which will become a challenge to hydrologic forecast, flood control and water resources planning [11].

\section{2) Streamflow analysis}

Table II presents CV of seasonal and annual runoff compared to the baseline period. As illustrated in Table II, the values of $\mathrm{CV}$ of the baseline period were larger than of future periods in each future period. In summer, winter and annual, even smaller than baseline period, the values of $\mathrm{CV}$ were increasing. The smaller CVs means that the variation of runoff among years at the same season is smaller, which is benefit to water resource management.

TABLE II: THE CV OF RUNOFF DURING THE BASELINE PERIOD AND FUTURE PERIOD

\begin{tabular}{llllll}
\hline \hline Scenario & Spring & Summer & Autumn & Winter & Year \\
\hline Baseline period & 0.18 & 0.17 & 0.2 & 0.08 & 0.12 \\
GCMs_2020s & 0.11 & 0.1 & 0.12 & 0.06 & 0.07 \\
GCMs_2050s & 0.11 & 0.14 & 0.13 & 0.05 & 0.09 \\
GCMs_2080s & 0.1 & 0.16 & 0.1 & 0.05 & 0.09 \\
\hline \hline
\end{tabular}




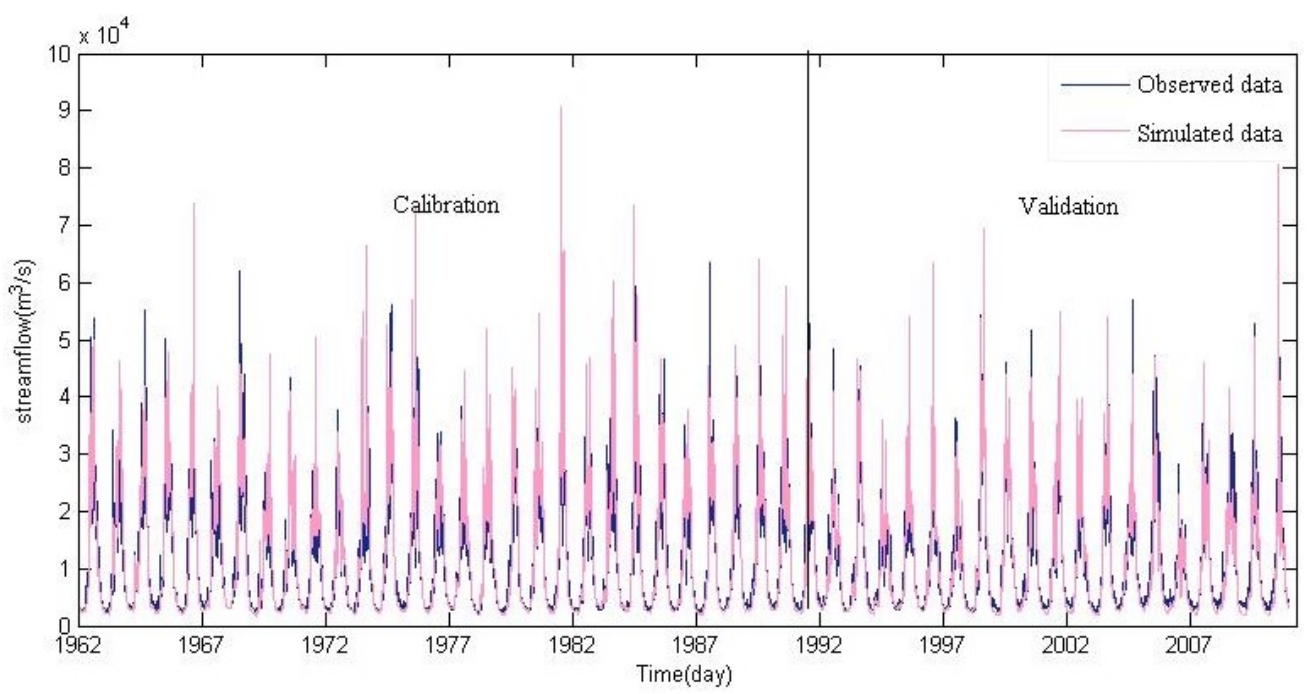

Fig. 2. The time series of the observed and simulated discharges of Cuntan stati.
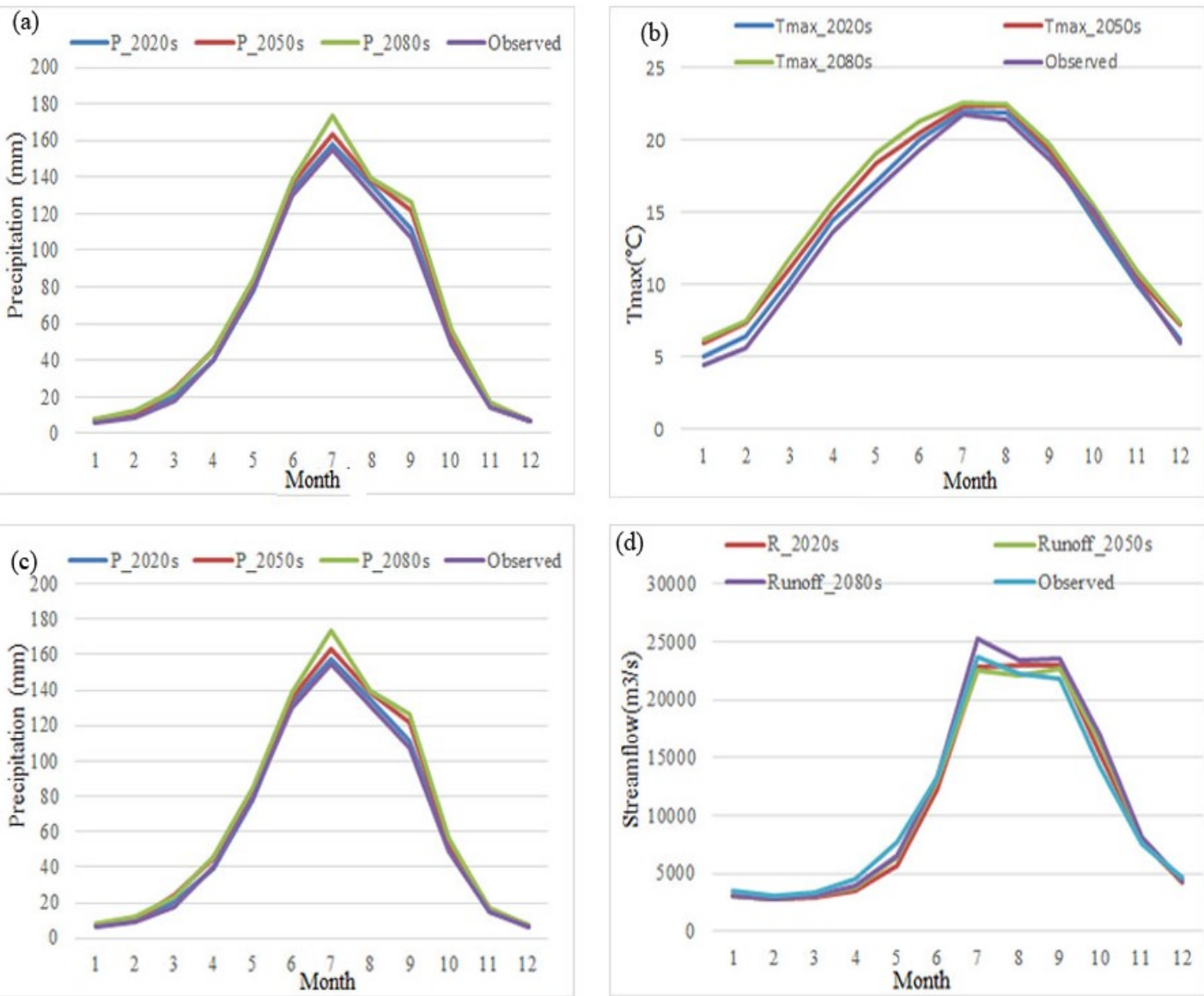

Fig. 3. Comparison of monthly mean precipitation, Tmax, Tmin and streamflows between historical data (1962-2010) and GCMs climate in three future periods.

\section{CONCLUSIONS}

In this study, VIC model was applied to the upper reaches of Yangtze River with the calibration period of 1962-1990, and validation period of 1991-2010. In both periods, the NSE values were greater than $80 \%$ and the values of RE were smaller than $3 \%$ at daily, monthly and yearly scales. This demonstrated that the VIC model can accurately reveal the rainfall-runoff processes. Five GCMs under RCP4.5 were projected to the calibrated VIC model to study the hydrological processes in three future periods (2020-2049,
2050-2079, 2080-2099).

The results showed that temperature will increase from July to September, the temperature will increase from January to June and other months shows no pronounced trends. The future streamflow will decrease slightly in January to June but increase from August to October. The intensified streamflow will put forward severe challenge to water resource management. Furthermore, the coefficient of variation $(\mathrm{CV})$ of seasonal and annual runoff was calculated. The results clearly showed that CV was increasing in summer and annual, decreasing in winter. In our future research, the uncertainty of 
VIC model and GCMs would be assessed.

\section{ACKNOWLEDGEMENTS}

The authors gratefully acknowledge support from the State Key Program of National Science of China (No. 51239004), the National Natural Science Foundation of China (No. $51309105)$

\section{REFERENCE}

[1] Y. Zhang, Q. You, C. Chen, and J. Ge, "Impacts of climate change on streamflows under RCP scenarios: A case study in Xin River Basin, China," Atmos. Res., pp. 178-179, 521-534, June 2016.

[2] R. R. Shrestha, D. L. Peters, and M. A. Schnorbus, "Evaluating the ability of a hydrologic model to replicate hydro-ecologically relevant indicators," Hydrol. Process, vol. 28, no. 14, pp. 4294-4310, Jan. 2014.

[3] D. H. Bae, T. Koike, J. A. Awan, M. H. Lee, and K. H. Sohn, "Climate change impact assessment on water resources and susceptibale zones identification in the Asian Monsoon Region," Water Resour. Manag., vol. 29, no. 14, pp. 5377-5393, May 2015.

[4] X. Liang, "A simple hydrologically based model of land-surface water and energy fluxes for general-circulation models," J. Geophys. Res. vol. 99, no. D7, pp. 14415-14428, May 1994.

[5] X. Liang, "Surface soil moisture parameterization of the VIC-2L model: Evaluation and modification," Global Planet. Change., vol. 13, no. 1-4, pp. 195-206, Nov 1996,

[6] D. Yan, S. E. Werners, F. Ludwig, and H. Q. Huang, "Hydrological response to climate change: The Pearl River, China under different RCP scenarios," J. hydrol. vol. 4, pp.228-245, Apr 2015.

[7] D. Park and M. Markus, "Analysis of a changing hydrologic flood regime using the Variable Infiltration Capacity model." J. Hydrol., vol 515, pp. 267-280. Sep 2014.

[8] D. N. Khoi, and T. Suetsugi, "Hydrologic response to climate change: A case study for the Be River Catchment, Vietnam," J. Water and Clim. Chang., vol. 3, no. 3, pp. 207-224, Aug. 2012.

[9] R. Knutti and J. Sedláček, "Robustness and uncertainties in the new CMIP5 climate model projections," Nat. Clim. Chang., vol. 3, no. 4, pp. 369-373, Aug 2013.
[10] D. Zuo, Z. Xu, and J. Zhao, "Abbaspour, K. C., Yang, H., Response of runoff to climate change in the Wei River basin, China," Hydrol. Sci. J., vol. 60 , no. 3 , pp. 508-522, Jun. 2015

[11] Y. Zhang, Q. You, H. Lin, and C. Chen, "Analysis of dry/wet conditions in the Gan River Basin, China, and their association with large-scale atmospheric circulation," Glob. Planet.Chang. vol. 133, pp.309-31. Sep 2015.

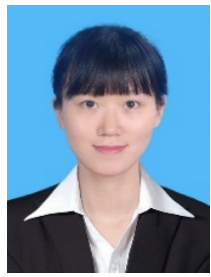

Changqing Meng was born in February 1989 in China She is a Ph.D student in hydrology in 2013, in Huazhong University of Science and Technology, Wuhan, China. Her major is in hydrology and water resources management.

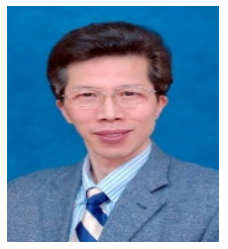

Jianzhong Zhou is the dean of the School of Hydropower and Information Engineering, Huazhong University of Science and Technology, Wuhan, China.

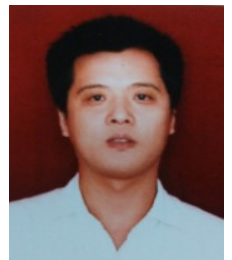

Minglong Dai was born in Auguest 1979 in China. He is Ph.D student in hydrology in Huazhong University of Science and Technology, Wuhan, China.

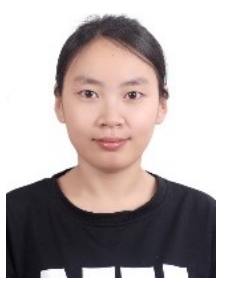

Wei Li was born in June 1987 in China. She is Ph.D student in hydrology in Huazhong University of Science and Technology, Wuhan, China. 